\title{
An Explanatory Model to Guide Assessment, Risk and Diagnosis of Psychological Distress after Abortion
}

\author{
Maureen Curley \\ College of Nursing, University of Florida, Gainesville, USA \\ Email: maureencurley@ufl.edu
}

Received 20 August 2014; revised 15 September 2014; accepted 12 October 2014

Academic Editor: Yasam Kemal Akpak, Ankara Mevki Military Hospital, Turkey

Copyright (C) 2014 by author and Scientific Research Publishing Inc.

This work is licensed under the Creative Commons Attribution International License (CC BY). http://creativecommons.org/licenses/by/4.0/

(c) (i) Open Access

\begin{abstract}
Background: Emerging data report 30\% of women worldwide who obtain elective abortion experience negative and persistent psychological distress afterward. Studies find higher rates of psychological stress, depressive, substance, and anxiety disorders as well as suicidal behaviors, among some populations after abortion as compared to other reproductive events. Of concern, is that current theory and practice which promote abortion to relieve the stress of an unwanted pregnancy do not reflect new evidence. Moreover, the controversy on abortion inhibits research and treatment on its impact on women's mental health. Thus, clinicians do not identify adverse psychological outcomes to abortion leaving many women untreated. Indeed, this knowledge-practice gap among healthcare providers may be the major reason that the incidence of adverse psychological outcomes after abortion continues to rise. Method: This paper proposes a theoretical understanding of psychological distress after abortion based on new data. A bio-psychosocial framework, including a psychological and biological theory, as well as a conceptual model is presented to explain the development of psychological distress after abortion. A comparison of risk factors between postpartum and post-abortion disorders is presented. Conclusion: A new theoretical model of psychological distress after abortion deepens understanding of the range of women's responses to abortion and promotes evidence based practice. A scientific framework provides a much needed understanding of abortion aftermath as opposed to a political one. By providing assistance to clinicians in the identification, screening, and treatment of psychological disorders after abortion, this thesis aims to close the practice gap, and increase services after abortion to women who need them.
\end{abstract}

\section{Keywords}

Abortion, Mental Health, Theory, Psychological Risk 


\section{Introduction}

Over one third of women worldwide who obtain elective abortions experience significant psychological distress afterwards [1]. Such post-abortion psychological distress includes higher rates of depression [2]-[5], suicide [6] [7], anxiety [2] [8], sleep problems [9], and substance disorders [10] compared to other reproductive events. Of particular concern, is the increased evidence of women experiencing post-traumatic stress disorders after abortion [11]-[15], which appears independent of age, geographic location, or ethnicity.

Following abortion, mental health disorders develop along several different pathways. The stress of the abortion itself may be one pathway which contributes to adverse mental health outcomes afterwards, and independently contributes to a full or partial episode of Post-Traumatic Stress Disorder (PTSD) for some women [8] [11] [16]-[18]. Some women experience immediate, chronic or delayed psychological stress and trauma disorders as a result of abortion [2] [11] [18]-[20]. Untreated chronic or delayed PTSD following other traumatic events can manifest as subsequent depression, anxiety, or self-destructive behaviors. Untreated PTSD following an abortion can manifest as depressive, self-destructive behaviors, including suicide, and anxiety disorders.

Mental health problems which existed prior to the abortion pose another potential pathway which can lead to deteriorating mental health afterwards. Some researchers ascribe post-abortion psychological distress to preabortion distress, where little distress is attributed to the abortion itself [21] [22], thus minimizing the negative impact that abortion has for some populations of women. Unfortunately, this view prevails within some aspects of healthcare and contributes to the lack of recognition of PAD. A third pathway suggests that abortion may partially contribute to psychological distress afterwards by exacerbating or compounding existing mental health problems, such as delayed PTSD from earlier adverse life events, or unresolved developmental conflicts. In such cases, the abortion may not relieve or diminish distress but add to latent distress. Finally, various factors surrounding the unintended pregnancy and abortion experience may pose a fourth potential pathway contributing to severe psychological distress after abortion. These may include conflicted, threatened, or ended relationships with the pregnancy partner, seeing the fetus on ultrasound, or on expulsion from medical abortions, as well as complications associated with the abortion procedure [2] [11].

The etiology of psychological distress after abortion remains controversial and has long generated political debate. Such controversy inhibits the development of effective treatment to relieve post abortion distress, especially for high risk populations, such as younger women. This is worrisome as younger women aging twentyfour and under represent those having the most abortions. The large number of abortions in this age group represents a highly significant, yet largely unrecognized problem within healthcare. Of further concern is that many healthcare providers are unaware of new data linking abortion to adverse psychiatric sequelae for some populations, which further inhibits women from receiving treatment.

\section{Purpose}

This paper aims to provide a comprehensive explanation of post-abortion psychological distress (PAD) in accordance with new data. We enlisted the services of a trained medical librarian to conduct a systematic review of human studies published in English from 1990 through April 2013, examining outcomes of induced, voluntary, and legal abortion on women's mental health. Databases included PubMed, Medline, Psych Info, BIOSIS, Web of Science, the PILOTS Data base, and Cochrane Collaboration of Systematic Reviews. Our results showed a large number of studies which provide evidence to support PAD, yet no explanatory model to understand PAD. Thus, we propose a mechanism for healthcare providers to understand, identify, and evaluate women who develop PAD. PAD refers to severe and persistent negative psychological, emotional, and behavioral responses to an induced, legal, and elective abortion. Because the etiology of PAD remains poorly understood, we provide a detailed account, including: 1) a bio-psycho-social approach including proposed biological mechanisms underlying PAD, 2) a psychological theory and conceptual model of PAD, 3) identifiable risk factors to screen for PAD, and 4) a guide to assess and evaluate PAD. PAD is clinically significant and ranges from mental disorders which are sub-syndromal to those meeting psychiatric diagnostic criteria according to the Diagnostic and Statistical Manual of Mental Disorders, Fifth Edition, (DSM-5) [23] or the International Classification of Diseases, Ninth Edition (ICD-9) [24].

\section{A Bio-Psycho-Social Paradigm}

In his treatise on scientific change, Kuhn (1977) asserts that old paradigms submit to new advances in know- 
ledge [25]. A political paradigm has shaped the abortion issue within healthcare. Healthcare providers promote abortion to eliminate the stress of an unintended pregnancy, and assume women who choose to terminate will experience relief. In fact, one in three women do not [1], and the incidence of PAD is higher than previously estimated. This assumption excludes women who choose abortion and experience adverse mental health outcomes afterwards, women who choose abortion and regret it, or women who choose abortion because they feel pressured by partners, families, or circumstances. Healthcare providers have been slow to recognize these women.

In contrast to a political paradigm, a bio-psycho-social framework describes women's responses to abortion from a bottom up as opposed to top down approach, and provides a mechanism to explain individual variations to abortion. A bio-psycho-social perspective applies Maslow's Hierarchy of Needs, a universal principle of healthcare, to the human experience of terminating a pregnancy. Maslow proposes human needs are sequentially ordered from basic survival to the full human potential, where lower needs are fulfilled before higher ones. The hierarchy includes five domains: 1) physiological, 2) safety and security, 3) love and belongingness, 4) self-esteem, and 5) self-actualization [26].

Applying Maslow's framework to abortion, and similar other reproductive events [27], abortion is first, a biological experience. From a biological perspective, responses to abortion are understood within the sequenced context of physiological, emotional, psychological, familial, social and political domains. Ideally, examination of PAD would start at the physiological domain and include critical neurobiological processes. Neurobiological investigation of PAD includes examining the impact of abortion on stress hormones, neurotransmitter activity, and gonadal hormones.

Surprisingly, no studies were found on the impact of abortion on cortisol levels to examine the physiological effects of PAD. Likewise, no studies were found on the impact of abortion on neurotransmitter regulation to examine changes in serotonin or norepinephrine on mood and behavior. Nor were studies done on the impact of abortion on reproductive hormones to measure changes in estrogen levels, which play a major role in regulating mood, anxiety, stress and behavioral disorders after other reproductive events [27], and which potentially have a role in contributing to PAD. Despite this, the following section proposes an explanation of biological processes associated with psychological distress after abortion.

A bio-psychosocial approach is oriented toward health and illness as opposed to politics and required for clinical practice to reflect sound evidence. This framework includes a continuum of responses ranging from health to illness. Since psychological responses to abortion can range from emotional relief to severe emotional distress, women who experience no, minimal, or temporary psychological distress after abortion do not require healthcare services. However, women who experience significant and persistent psychological distress require healthcare services that typically don't exist within current practice environments. Based on over 1 million abortions per year in the United States, a 30\% incidence of PAD [1] yields over 300,000 women per year who remain untreated for PAD.

\section{Biological Responses to Psychological Distress}

According to McEwen (2003) allostasis refers to the concept of physiological stability during change which is adaptive and required for survival [28]. During allostasis, the hormonal stress response is activated to mediate daily and major life stressors. Stressors stimulate the amygdala and autonomic nervous system to release stress mediators, including hormones such as cortisol and catecholamines [29]. Adaptive stress mediators include initiation, continuation, and turning off stress hormones, such as cortisol, when no longer needed. This mechanism is protective in the short term, but can be detrimental in the long term, if the stress response is maladaptive.

Maladaptive stress responses result from too many adverse events, too severe a stressor, or from a hormonal dysfunction [28]. They fail to mediate stressors by over-activation, under-activation, or non-activation of stress hormones causing an imbalance which reflect a dys-regulation of the hypothalamus-pituitary-adrenal (HPA) axis including sustained activation of the amygdale. This results in allostatic load, an excessive psychological and physical strain resulting in chronic fatigue and functional decline [30] [31]. Allostatic load reflects an inability to mount an adequate stress response, and the cumulative impact of repeated attempts to manage stress.

McEwen describes four pathways to allostatic load including: (a) multiple and repetitive stressors, (b) inability to adapt to a single stressor, (c) delayed response to a stressor, and (d) inadequate hormonal response to a stressor. Allostatic load is associated with conditions of chronic psychological stress such as PTSD and major depressive disorders [28] [30] [31]. 


\section{Biological Responses to Psychological Distress after Pregnancy}

Allostatic load was studied in pregnant women and found to be associated with postpartum disorders. Allostatic load and its associated variations in the HPA axis and cortisol levels are independent of the stress incurred from the pregnancy itself. During normal gestation, the HPA axis attenuates for changes in cortisol. Pregnant women with cumulative or adverse psychosocial stressors, coupled with poor coping skills, were found to experience dysregulation in the Hypothalamic Pituitary Adrenal (HPA) axis, suggesting an increased allostatic load and greater risk for postpartum disorders [32] [33]. Likewise, Talge, Neal, and Glover found variations in the HPA axis associated with both discrete stressors during pregnancy, such as the death of a loved one, surviving a hurricane, or adverse birth outcomes, and ongoing stressors during pregnancy such as mood or anxiety disorders [34]. These correlate with two of McEwen's causal pathways including allostatic load resulting from multiple and repetitive stressful life events, and allostatic load resulting from the inability to adapt to a single stressor [28] [30].

We propose the concept of allostatic load to measure biological mechanisms underlying PAD, since no data on allostatic load after abortion were found. Allostatic load after abortion describes the cumulative, inadequate physiological responses to the demands of stress from abortion and offers a step toward understanding PAD.

\section{Biological Responses to Psychological Distress after Abortion}

Conceivably, women who experience severe or prolonged psychological stress after abortion may have insufficient coping skills to adjust and may reflect inadequate hormonal responses to terminating pregnancy. The stress response activates upon confirmation of an unintended pregnancy and is sustained and heightened during pregnancy progression. Additionally, abortion may impose a secondary physiological stress response due to abrupt surgical termination of pregnancy. Moreover, the knowledge and witness of the death of the unborn child meets the DSM 5 criteria for Acute Stress and PTSD.

After abortion, stress responses either resolve, as in the case of those who experience relief, or worsen in cases of acute, chronic, or latent PAD. Women who experience PAD appear unable to mount a sufficient hormonal response to the abortion experience, resulting in psychological disorders.

Applying McEwens' concepts of allostatic load to abortion, this may manifest from any of the four pathways including: (a) multiple stressors, including multiple abortions or unresolved stressors prior to abortion, (b) a single abortion, (c) delayed response to abortion, and (d) from an inadequate response to abortion. On the first pathway, a woman may experience multiple stressors such as early adverse life events, including physical, emotional, or sexual abuse which may not have been addressed prior to the unintended pregnancy and abortion. This cumulative stress response explains women who may have an allostatic load prior to abortion, and this may be compounded after abortion. This pathway also illuminates that mental health problems occurring after abortion result from mental health problems that preceded abortion. This pathway may also explain how allostatic load can develop after the cumulative stressors of multiple abortions.

In the second pathway, allostatic load may develop from an inability to adapt to a single stressor and results from being unable to adapt to a single and particularly first abortion experience. For those who received inadequate pre-abortion counseling, the abortion may exceed internal coping skills, or external resources. The abortion experience may independently contribute to psychological distress afterwards. This pathway targets younger women who are most at risk for PAD due to limited coping skills and development. Further, this mechanism suggests that allostatic load can occur from the impact of a single stressor even in the wake of previous stressors. For example, Young, Tolman, Witkowski and Kaplan (2004) examined salivary cortisol levels on a sample of women with a history of multiple stressors. They found that lowered cortisol levels reflected recent as opposed to chronic conditions of stress [35]. This suggests that while some women may experience variations in cortisol levels from stressors which precede the abortion experience, others may experience variations in cortisol levels as a result of the stress of the abortion experience even in the face of prior stressors. Similar studies testing cortisol after abortion need to be conducted.

The third pathway of allostatic load may develop from a delayed stress response to abortion. There is an absence of PAD after abortion, followed by emergence of PAD over time as a result of allostatic load. When adaptive resolution does not occur, delayed stress responses may become chronic. Many women experience an eight to twelve year delay in PAD [19], where distress from an earlier abortion is awakened by a subsequent pregnancy, or other stressful event.

For the fourth pathway, a woman may experience inadequate hormonal response to abortion resulting in 
allostatic load. This may be due to dys-regulated activity of the HPA axis associated with psychological distress after reproductive events, including abortion. Glynn, Davis, and Sandman (2013) found that maternal HPA dysregulation predicted postpartum depression due to adrenal insufficiency as well as changes in the HPA sensitivity to cortisol [36]. During normal pregnancy, cortisol levels increase threefold by the end of the third trimester [37]. While data correlating changes in cortisol levels associated with postpartum depression is inconclusive, a few studies have found evidence that elevated cortisol levels both during pregnancy [38] and afterwards [39] [40] predicted postpartum depression. Dysregulation of the HPA axis and subsequent variation in cortisol levels may be associated and predictive of women who experience PAD.

Abortion, as a type of pregnancy outcome, is a biological experience. Similar to other perinatal mood and anxiety disorders, PAD may reflect variations in levels of reproductive hormones. Changes in sensitivity to estrogen signaling predict postpartum disorders [41] and could potentially contribute to PAD. Since estrogen regulates women's moods, changes during reproductive events are associated with perinatal mood and anxiety disorders, particularly post-partum depression [42] [43]. Estrogen theory suggests that during pregnancy estrogen levels increase to almost 200 times their normal level. During labor, the mood regulator estrogen withdraws, leaving some women biologically sensitive and prone to postpartum depression. The estrogen signaling theory provides another biological mechanism to explain mood reactions after abortion. This abrupt change in estrogen may pose a risk for hypersensitivity and result in mood reactions after abortion. Exploratory studies evaluating variations in estrogen associated with induced abortion and its impact on subsequent mental health need to be conducted.

Doornbos, Fokkema, Molhoek, Tanke, et al. (2008) studied hormonal changes in rats who were treated with estrogen to simulate pregnancy. They examined symptoms of postpartum depression (PPD) by measuring the stress response of the HPA axis to the withdrawal of hormones. Results showed fast withdrawal of hormones resulted in increased stress response and symptoms of vigilance and anxiety compared to prolonged withdrawal of hormones [44]. Estrogen withdraws much more rapidly during abortion than delivery and could be attributed to PAD.

\section{Biological Responses to Psychological Distress after Abortion}

PAD shares risk factors with postpartum psychological disorders, including pre-morbid psychopathology, early adverse life events, poor social support, previous abortion [45], younger age, single status, unsatisfactory interpersonal relationships [46], and concealment of pregnancy [47]. Risk factors for PAD include pre-morbid psychopathology [48] younger age [49], concealment of pregnancy from significant others [50], single status, poor social support [51], conflicted relationship with mother, and late trimester abortion [19], obstetrical complications during the abortion, such as prolonged bleeding, and viewing the embryo prior to the abortion procedure [11].

Some risk factors for postpartum mood disorders are amenable to intervention. Similar risk factors for PAD may be amenable to intervention, as well. These include lack of social support, inadequate pre-abortion counseling, unrealistic abortion expectations, such as the emotional impact or time required to adjust, and limited coping skills. See Table 1.

\section{Theoretical Framework for Psychological Distress after Abortion}

Speckhard and Rue (1992) first proposed abortion as a traumatic event for some, and numerous studies have confirmed this claim. We expand this by proposing Horowitz's theory of Psychological Stress Responses as a framework to explain the development of PAD, and to understand emerging evidence [52]. Horowitz' theory provides the underlying construct for the diagnostic criteria for Acute Stress Disorder and Post-Traumatic Stress Disorders (PTSD) in the American Psychiatric Association Diagnostic and Statistical Manual of Mental Disorders, Fifth Edition (DSM-5) [23]. Additionally, Horowitz, Wilner, and Alverez (1979) developed the well-validated Impact of Event Scale which has been used extensively to identify and measure the cardinal symptoms of PTSD) [53], and used in studies to detect PTSD in women after abortion. In addition, we propose a conceptual model to guide future research and clinical practice.

The theory suggests stress responses occur in phases [52] [53]. The hallmark of a stress response is the bi-phasic alternation of re-experiencing intrusive and avoidant symptoms of a stressful event. Horowitz defines a stressful life event as one "not fully in accord with a person's usual inner working models" (Horowitz, 2001, p. 119). See Table 2. 
Table 1. A comparison of risk factors for psychological distress post-abortion and psychological distress postpartum.

\begin{tabular}{|c|c|c|}
\hline Risk Factors & Post Abortion & Postpartum \\
\hline \multirow[t]{3}{*}{ Biological Factors } & Pre-morbid psychopathology & Pre-morbid psychopathology \\
\hline & Early adverse life events & Early adverse life events \\
\hline & History of sex/physical abuse & History of sex/physical abuse \\
\hline \multirow[t]{5}{*}{ Psychosocial Factors } & Lack partner support & Lack partner support \\
\hline & Social isolation & Social isolation \\
\hline & Concealment of pregnancy/abortion & Concealment of pregnancy \\
\hline & Feel forced to abort & Feel forced to deliver \\
\hline & Conflicted feelings toward fetus & Conflicted feelings toward fetus \\
\hline \multirow[t]{5}{*}{ Individual Factors } & Younger age & Younger age \\
\hline & Negative relationship with mother & Negative relationship with mother \\
\hline & Previous abortion(s) & Previous abortion(s) \\
\hline & Conservative values & \\
\hline & Maternal characteristics & \\
\hline \multirow[t]{5}{*}{ Obstetrical Factors } & Physical complications & Physical Complication \\
\hline & Unsatisfactory abortion experience & Unsatisfactory delivery \\
\hline & Inadequate pre-abortion counseling & Inadequate childbirth education \\
\hline & Late trimester abortion & \\
\hline & Viewing embryo/fetus & \\
\hline
\end{tabular}

Table 2. Phases of psychological distress after abortion adapted from stress response syndromes.

\begin{tabular}{|c|c|c|c|}
\hline $\begin{array}{l}\text { Normal Phrases of } \\
\text { Stress Response }\end{array}$ & $\begin{array}{l}\text { Abnormal Phases of } \\
\text { Stress Response }\end{array}$ & $\begin{array}{l}\text { Pathological Behaviors of } \\
\text { Psychological Distress }\end{array}$ & $\begin{array}{l}\text { Pathological Behaviors of } \\
\text { Post Abortion Psychological Distress }\end{array}$ \\
\hline Outcry & Intense or prolonged & Panic, exhaustion & Panic, confusion, emotional numbing, decides to abort \\
\hline Denial & Intense or prolonged & $\begin{array}{l}\text { Pathological avoidance, } \\
\text { depression, drugs, suicide }\end{array}$ & $\begin{array}{l}\text { Pathological avoidance, } \\
\text { depression, drugs, suicide }\end{array}$ \\
\hline Intrusion & Intense or prolonged & Post-traumatic stress reactions & Post-traumatic stress \\
\hline Working Through & Blocked & Maladaptive coping & Maladaptive coping \\
\hline Completion & Not reached & Personality Constriction & Impairment of functioning \\
\hline
\end{tabular}

An unwanted pregnancy poses a life-altering event for a single young woman, and the decision to abort often signals the severity of desperation. Adapting Horowitz's phases of a stress response to abortion, they are as follows: the first stressful event is news of pregnancy confirmation. The outcry phase over the pregnancy follows, which may include symptoms of panic, emotional numbing, or dissociation, i.e., detachment from reality. This experience during the outcry phase is pivotal to understanding PAD, as many decide to abort within this mental state, and remain emotionally numb or panic-stricken until well beyond the experience.

The abortion procedure is the second stressful event. The outcry phase is heightened at the completion of the abortion. If the abortion experience is not intense or prolonged, normal phases of stress response progress through denial, intrusion, and working through until completion. If, however, the abortion experience is intense or prolonged, conceivably in cases of allostatic load, then abnormal phases of denial and intrusion will occur, resulting in a pathological response and completion will not be reached. Pathological responses consist of efforts to avoid confronting the abortion experience and manifests as negative coping. 
Negative coping includes avoiding painful feelings such as depression, sadness, or guilt, and often results in acting out behaviors such as high-risk sexual or self-destructive activity, including suicidal activity, secondary substance abuse and other addictions. The denial phase alternates with the intrusive phase, which often includes distressing memories of abortion such as how the baby would look, how old the baby would be at different times, baby dreams, unexpected images of the baby, and intense emotions of regret and ambivalence. If the abortion was medically induced, the women was given medication and expelled the fetus at home, the intrusive images may actually be memories of the aborted fetus, as women are required to inspect the fetal remains to ensure completion.

\section{Conceptual Model for Post Abortion Psychological Distress}

Literature describes PAD as psychological stress or a type of perinatal loss, and can be a synthesis of these two concepts. Stress response symptoms include distressing cognitive and emotional recollections of the unwanted pregnancy and abortion events, alternating with efforts to avoid these recollections. Research describes intrusive symptoms of anxiety, sleep disruptions, difficulty concentrating, crying spells, vivid images, and preoccupation with the pregnancy or abortion. Speckhard \& Rue attribute guilt from abortion to a type of "survivor guilt". Avoidant symptoms include denial, secrecy, or non-disclosure of the abortion to significant others, emotional numbing, and secondary substance abuse [19].

For the second concept, perinatal grief emerges as response to perinatal loss. Angelo (1992) describes perinatal grief after abortion as depression, despair, hopelessness, complicated grief, and protracted guilt which impaired functioning [54]. PAD as a synthesis of psychological stress and grief was empirically validated in an international study by the authors of $n=151$ self-selected university students where 89 students had obtained abortions. All students who had abortions reported symptoms of severe psychological stress and moderate perinatal grief specific to the target pregnancy which persisted three years [11]. See Figure 1.

\section{Conclusions}

Health care has a tradition of patient advocacy, particularly for marginalized populations. Abortion is one of the most frequently performed procedures in the world. Yet women report being shunned and marginalized by health care providers in general and mental health professionals in particular who deny or minimize their experience of PAD. Healthcare providers are accountable to the public and must recognize, treat and investigate women who report PAD. Some aspects of health care, such as abortion, have sociopolitical implications, yet biological and psychological processes cannot be ignored or minimized. A bio-psychosocial approach to abortion reflects sensitive, patient centered, humanistic practice. Evidence of increased incidence of PAD outpaces traditional ways of clinical practice, and must be addressed as a public health priority.

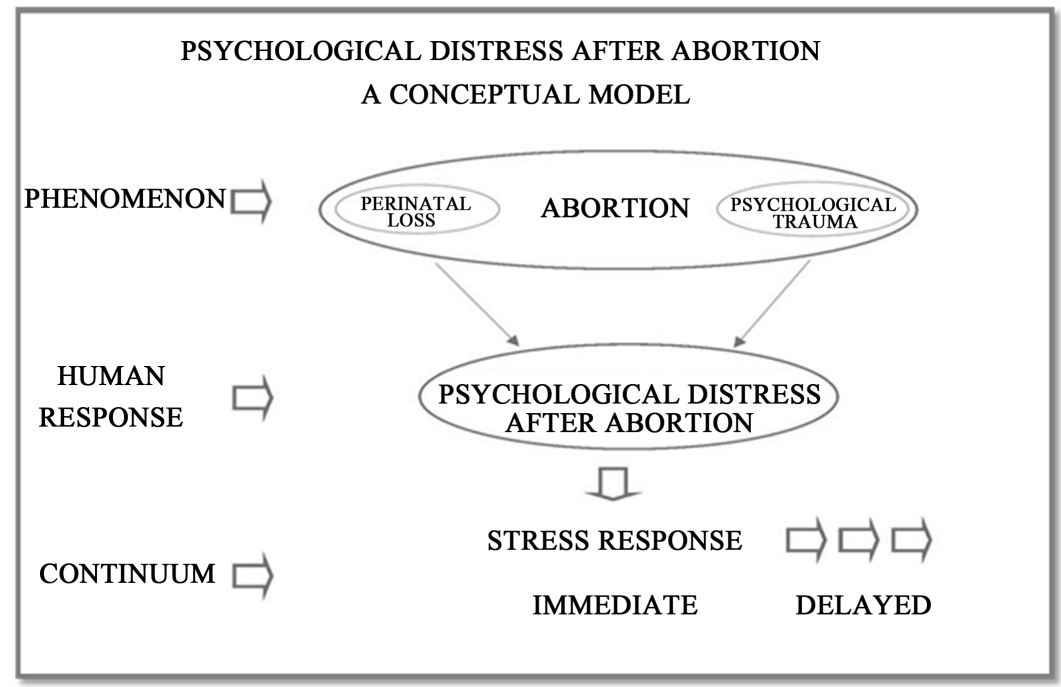

Figure 1. Conceptual model for psychological distress after abortion (PAD). 
Healthcare professionals have an ethical obligation to identify, monitor, and treat women experiencing adverse psychological outcomes to abortions. This paper provides a theory and framework to recognize and understand women who experience PAD. A detailed conceptual model is outlined including the psychological and scientific underpinnings of responses to abortion in a much-needed effort to fill a gap clouded by politics.

In tandem with the Institute of Medicine's initiative to improve patient safety [55], we prioritized vulnerable populations by identifying risk factors for PAD. Prevention strategies for PAD include screening and monitoring populations at highest risk. Informed consent protocol for abortion would reflect these new risks. Treatment based on evidence would be offered to women and patient outcomes would be evaluated.

A public health agenda for PAD includes developing education strategies, such as within school-based health education programs. Programs would identify real risks associated with all reproductive decision-making including abortion before pregnancy occurs or before students become sexually active. Education would also include increasing professional awareness of post abortion responses through knowledge transfer efforts such as continuing education, university courses, etc.

\section{References}

[1] Bradshaw, Z. and Slade, P. (2003) The Effects of Induced Abortion on Emotional Experiences and Relationships: A Critical Review of the Literature. Clinical Psychology Review, 23, 929-958. http://dx.doi.org/10.1016/j.cpr.2003.09.001

[2] Fergusson, D., Horwood, J. and Boden, J.M. (2008) Abortion and Mental Health Disorders: Evidence from a 30-Year Longitudinal Study. British Journal of Psychiatry, 193, 444-451. http://dx.doi.org/10.1192/bjp.bp.108.056499

[3] Dingle, K., Alati, A., et al. (2008) Pregnancy Loss and Psychiatric Disorders in Young Women: An Australian Birth Cohort Study. British Journal of Psychiatry, 193, 455-460. http://dx.doi.org/10.1192/bjp.bp.108.055079

[4] Pederson, W. (2008) Abortion and Depression: A Population-Based Longitundinal Study of Young Women. Scandinavian Journal of Public Health, 36, 424-428. http://dx.doi.org/10.1177/1403494807088449

[5] Taft, A.J. and Watson, L.F. (2008) Depression and Termination of Pregnancy in a National Cohort of Young Australian Women: The Confounding Effect of Women Experiencing Violence. BioMedCentral, 8, 75.

[6] Gilchrist, A.C., Hannaford, P.C., Frank, P. and Kay, C.R. (1995) Termination of Pregnancy and Psychiatric Morbidity. The British Journal of Psychiatry, 167, 243-248. http://dx.doi.org/10.1192/bjp.167.2.243

[7] Gissler, M., Hemminki, E. and Lonnqvist, J. (1996) Suicides after Pregnancy in Finland 1987-1994: Register Linkage Study. BMJ, 313, 1431-1434. http://dx.doi.org/10.1136/bmj.313.7070.1431

[8] Cougle, J., Reardon, D. and Coleman, P. (2005) Generalized Anxiety following Unintended Pregnancies Resolved through Childbirth and Abortion: A Cohort Study National Survey of Family Youth. Journal of Anxiety Disorders, 19, 137-142. http://dx.doi.org/10.1016/j.janxdis.2003.12.003

[9] Reardon, D.C. and Coleman, P.K. (2006) Relative Treatment Rates for Sleep Disorders and Sleep Disturbances Following Abortion and Childbirth: A Prospective Record-Based Study. Sleep, 29, 105-106.

[10] Reardon, D.C. and Ney, P.G. (2000) Abortion and Subsequent Substance Abuse. American Journal of Drug and Alcohol Abuse, 26, 61-75. http://dx.doi.org/10.1081/ADA-100100591

[11] Curley, M. and Johnston, C. (2013) The Characteristics and Severity of Psychological Distress after Abortion among University Students. Journal of Behavioral and Health Service and Research, 40, 279-293. http://dx.doi.org/10.1007/s11414-013-9328-0

[12] Hamana, L., Rausch, S., Sperlich, M. and Defever, E. (2010) Previous Experience of Spontaneous Abortion or Elective Abortion and Risk for Post Traumatic Stress and Depression during Subsequent Pregnancy. Depression and Anxiety, 27, 699-707.

[13] van Emmerik, A.P., Kamphuis, J.H. and Emmelkamp, P.M. (2008) Prevalence and Prediction of Re-Experiencing and Avoidance after Elective Surgical Abortion: A Prospective Study. Clinical Psychology and Psychotherapy, 15, 378385.

[14] Rue, V., Coleman, P., Rue, J. and Reardon, D. (2004) Induced Abortion and Traumatic Stress: A Preliminary Comparison of American and Russian Women. Medical Science Monitor, 10, SR5-SR16.

[15] Zulčić-Nakić, V., Pajević, I., Hasanović, M. and Pavlović, S. (2012) Psychological Problems Sequelae in Adolescents after Artificial Abortion. Journal of Pediatric and Adolescent Gynecology, 25, 241-247. http://dx.doi.org/10.1016/j.jpag.2011.12.072

[16] Coleman, P.K. (2011) Abortion and Mental Health: Quantitative Synthesis and Analysis of Research Published 19952009. The British Journal of Psychiatry, 199, 180-186. http://dx.doi.org/10.1192/bjp.bp.110.077230 
[17] Coleman, P.K., Coyle, C.T., Shuping, M. and Rue, V.M. (2009) Induced Abortion and Anxiety, Mood, and Substance Abuse Disorders: Isolating the Effects of Abortion in the National Comorbidity Survey. Journal of Psychiatric Research, 43, 770-776. http://dx.doi.org/10.1016/j.jpsychires.2008.10.009

[18] Broen, A., Moum, T., Bodtker, A. and Ekeberg, O. (2005) The Course of Mental Health after Miscarriage and Induced Abortion: A Longitudinal, Five-Year Follow-Up Study. BMC Medicine, 3, 18. http://dx.doi.org/10.1186/1741-7015-3-18

[19] Speckhard, A.C. and Rue, V.M. (1992) Post Abortion Syndrome: An Emerging Public Health Concern. Journal of Social Issues, 48, 95-119. http://dx.doi.org/10.1111/j.1540-4560.1992.tb00899.x

[20] Ekblad, M. (1955) Induced Abortion on Psychiatric Grounds: A Follow-Up Study of 479 Women. Acta Psychiatrica Neurologica Scandinavia Supplement, 99, 1-238.

[21] Charles, V., Polis, C., Sridhara, S. and Blum, R. (2008) Abortion and Long-Term Mental Health Outcomes: A Systematic Review of the Evidence. Contraception, 78, 436-450. http://dx.doi.org/10.1016/j.contraception.2008.07.005

[22] Robinson, G., Stotland, N., Russo, N., Lang, J. and Occhiogrosso, M. (2009) Is There an “Abortion Trauma Syndrome”? Critiqueing the Evidence. Harvard Review of Psychiatry, 17, 268-269. http://dx.doi.org/10.1080/10673220903149119

[23] American Psychiatric Association (APA) (2013) Diagnostic and Statistical Manual of Mental Disorders. 5th Edition, APA, Arlington.

[24] WHO Organization (1990) International Classification of Diseases. 9th Revision, WHO, Geneva.

[25] Kuhn, T.S. (1977) Second Thoughts on Paradigms. In: Kuhn, T.S., Ed., The Essential Tension: Selected Studies in Scientific Tradition and Change, University of Chicago Press, Chicago, 293-320.

[26] Maslow, A.H. (1943) A Theory of Human Motivation. Psychological Review, 50, 370-396. http://dx.doi.org/10.1037/h0054346

[27] Sichel, D. (2003) Neurohormonal Aspects of Postpartum Depression and Psychosis. In: Spinelli, M.G., Ed., Infanticide: Psychosocial and Legal Perspectives on Mothers Who Kill, American Psychiatric Publishing \& APA, Washington DC, 61-80.

[28] McEwen, B.S. (2003) Mood Disorders and Allostatic Load. Biological Psychiatry, 54, 200-207. http://dx.doi.org/10.1016/S0006-3223(03)00177-X

[29] Kirschbaum, C., Kudielka, B.M., Gaab, J., Schommer, N.C. and Hellhammer, D.H. (1999) Impact of Gender, Menstrual Cycle Phase, and Oral Contraceptives on the Activity of the Hypothalamus-Pituitary-Adrenal Axis. Psychosomatic Medicine, 61, 154-162. http://dx.doi.org/10.1097/00006842-199903000-00006

[30] McEwen, B.S. (1998) Stress, Adaptation, and Disease: Allostasis and Allostatic Load. Annals of the New York Academy of Sciences, 840, 33-44. http://dx.doi.org/10.1111/j.1749-6632.1998.tb09546.x

[31] McEwen, B.S. and Wingfield, J.C. (2010) What's in a Name? Integrating Homeostasis, Allostasis and Stress. Hormones and Behavior, 57, 105-111. http://dx.doi.org/10.1016/j.yhbeh.2009.09.011

[32] Obel, C., Hedegaard, M., Henriksen, T.B., Secher, N.J., Olsen, J. and Levine, S. (2005) Stress and Salivary Cortisol during Pregnancy. Psychoneuroendocrinology, 30, 647-656. http://dx.doi.org/10.1016/j.psyneuen.2004.11.006

[33] Tu, M.T., Lupien, S.J. and Walker, C.D. (2005) Measuring Stress Responses in Postpartum Mothers: Perspectives from Studies in Human and Animal Populations. Stress, 8, 19-34. http://dx.doi.org/10.1080/10253890500103806

[34] Talge, N., Neal, C. and Glover, V. (2007) Antenatal Maternal Stress and Long-Term Effects on Child Neurodevelopment: How and Why. Journal of Child Psychology and Psychiatry, 48, 245-261. http://dx.doi.org/10.1111/j.1469-7610.2006.01714.x

[35] Young, E.A., Tolman, R., Witkowski, K. and Kaplan, G. (2004) Salivary Cortisol and Posttraumatic Stress Disorder in a Low-Income Community Sample of Women. Biological Psychiatry, 55, 621-626. http://dx.doi.org/10.1016/j.biopsych.2003.09.009

[36] Glynn, L.M., Davis, E.P. and Sandman, C.A. (2013) New Insights into the Role of Perinatal HPA-Axis Dysregulation in Postpartum Depression. Neuropeptides, 47, 363-370. http://dx.doi.org/10.1016/j.npep.2013.10.007

[37] Jung, C., Ho, J.T., Torpy, D.J., Rogers, A., Dooque, M., Lewis, J.G., et al. (2011) A Longitudinal Study of Plasma and Urinary Cortisol in Pregnancy and Postpartum. Journal of Endrocrinology \& Metabolism, 96, 1533-1540. http://dx.doi.org/10.1210/jc.2010-2395

[38] Handley, S.L., Dunn, T.L., Waldron, G. and Baker, J.M. (1980) Tryptophan, Cortisol and Puerperal Mood. British Journal of Psychiatry, 136, 498-508. http://dx.doi.org/10.1192/bjp.136.5.498

[39] Ehlert, U., Patalla, U., Kirschbaum, E., Piedemont, E. and Hellhammer, D.H. (1990) Postpartum Blues: Salivary Cortisol and Psychological Factors. Journal of Psychosomatic Research, 34, 319-325.

http://dx.doi.org/10.1016/0022-3999(90)90088-L 
[40] Pedersen, C.A., Stern, R.A., Pate, J., Senger, M.A., Bowes, W.A. and Mason, G.A. (1993) Thyroid and Adrenal Measures during Late Pregnancy and the Puerperium in Women Who Have Been Major Depressed or Who Become Dysphoric Postpartum. Journal of Affective Disorders, 29, 201-211. http://dx.doi.org/10.1016/0165-0327(93)90034-H

[41] Mehta, D., Newport, D.J., Frishman, G., Kraus, L., Rex-Haffner, M., Ritchies, J.C., Lori, A., Knight, B.T., et al. (2014) Early Predictive Biomarkers for Postpartum Depression Point to a Role for Estrogen Receptor Signaling. Psychological Medicine, Epub Ahead of Print.

[42] Davidson, B.J., Murray, R.D., Challis, J.R. and Valenzuela, G.J. (1987) Estrogen, Progesterone, Prolactin, Prostaglandin $E_{2}$, Prostaglandin $F_{2 \alpha}, 13,14-D i h y d r o-15-K e t o-P r o s t a g l a n d i n ~ F_{2 \alpha}$, and 6-Keto-Prostaglandin $F_{1 \alpha}$ Gradients across the Uterus in Women in Labor and Not in Labor. American Journal of Obstetrics and Gynecology, 157, 54-58. http://dx.doi.org/10.1016/S0002-9378(87)80345-9

[43] Löfgren, M. and Bäckströmxy, T. (1990) Serum Concentrations of Progesterone and 5 $\alpha$-Pregnane-3,20-Dione during Lr and Early Post Partum. Acta Obstetricia et Gynecologica Scandinavica, 69, 123-126. http://dx.doi.org/10.3109/00016349009006156

[44] Doornbos, B., Fokkema, D.S., Molhoek, M., Tanke, M.A., Postema, F. and Korf, J. (2009) Abrupt Rather than Gradual Hormonal Changes Induce Postpartum Blues-Like Behavior in Rats. Life Science, 84, 69-74. http://dx.doi.org/10.1016/j.lfs.2008.10.014

[45] Kumar, R. and Robson, K. (1978) Previous Induced Abortion and Ante-Natal Depression in Primiparae: Preliminary Report of a Survey of Mental Health in Pregnancy. Psychological Medicine, 8, 711-715. http://dx.doi.org/10.1017/S0033291700018912

[46] Spinelli, M.G. (1999) Prevention of Postpartum Mood Disorders. In: Postpartum Mood Disorders, American Psychiatric Association, Arlington, 217-235.

[47] Miller, L.J. (2003) Denial of Pregnancy. In: Spinelli, M.G., Ed., Infanticide: Psychosocial and Legal Perspectives on Mother Who Kill, American Psychiatric Publishing, Washington DC, 81-104.

[48] Mota, N., Burnett, M. and Sareen, J. (2010) Associations between Abortion, Mental Disorders, and Suicidal Behavior in a Nationally Representative Sample. The Canadian Journal of Psychiatry, 55, 239-247.

[49] Franz, W. and Reardon, D. (1992) Differential Aspects of Abortion on Adolescence. Adolescence, 105, 160-172.

[50] Major, B. and Gramzow, R.H. (1999) Abortion as Stigma: Cognitive and Emotional Implications of Concealment. Journal of Personality and Social Psychology, 77, 735-745. http://dx.doi.org/10.1037/0022-3514.77.4.735

[51] David, P., Rasmusen, N. and Holdt, E. (1980) Postpartum and Postabortion Psychotic Reactions. Family Planning Perspectives, 13, 88-91. http://dx.doi.org/10.2307/2134703

[52] Horowitz, M.J. (2001) Stress Response Syndromes. J. Aronson, New York.

[53] Horowitz, M., Wilner, N. and Alvarez, W. (1979) Impact of Event Scale: A Measure of Subjective Stress. Psychosomatic Medicine, 41, 209-218. http://dx.doi.org/10.1097/00006842-197905000-00004

[54] Angelo, E.J. (1992) Psychiatric Sequelae of Abortion: The Many Faces of Post Abortion Grief. Linacre Quarterly, 59, 69-80.

[55] Institute of Medicine Report (2000) To Err Is Human: Building a Safer Health System. National Academy Press, Washington DC. 
Scientific Research Publishing (SCIRP) is one of the largest Open Access journal publishers. It is currently publishing more than 200 open access, online, peer-reviewed journals covering a wide range of academic disciplines. SCIRP serves the worldwide academic communities and contributes to the progress and application of science with its publication.

Other selected journals from SCIRP are listed as below. Submit your manuscript to us via either submit@scirp.org or Online Submission Portal.
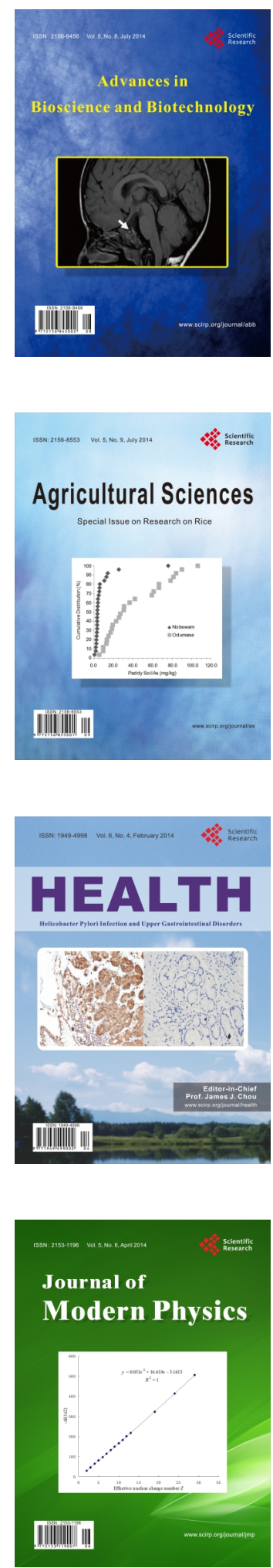
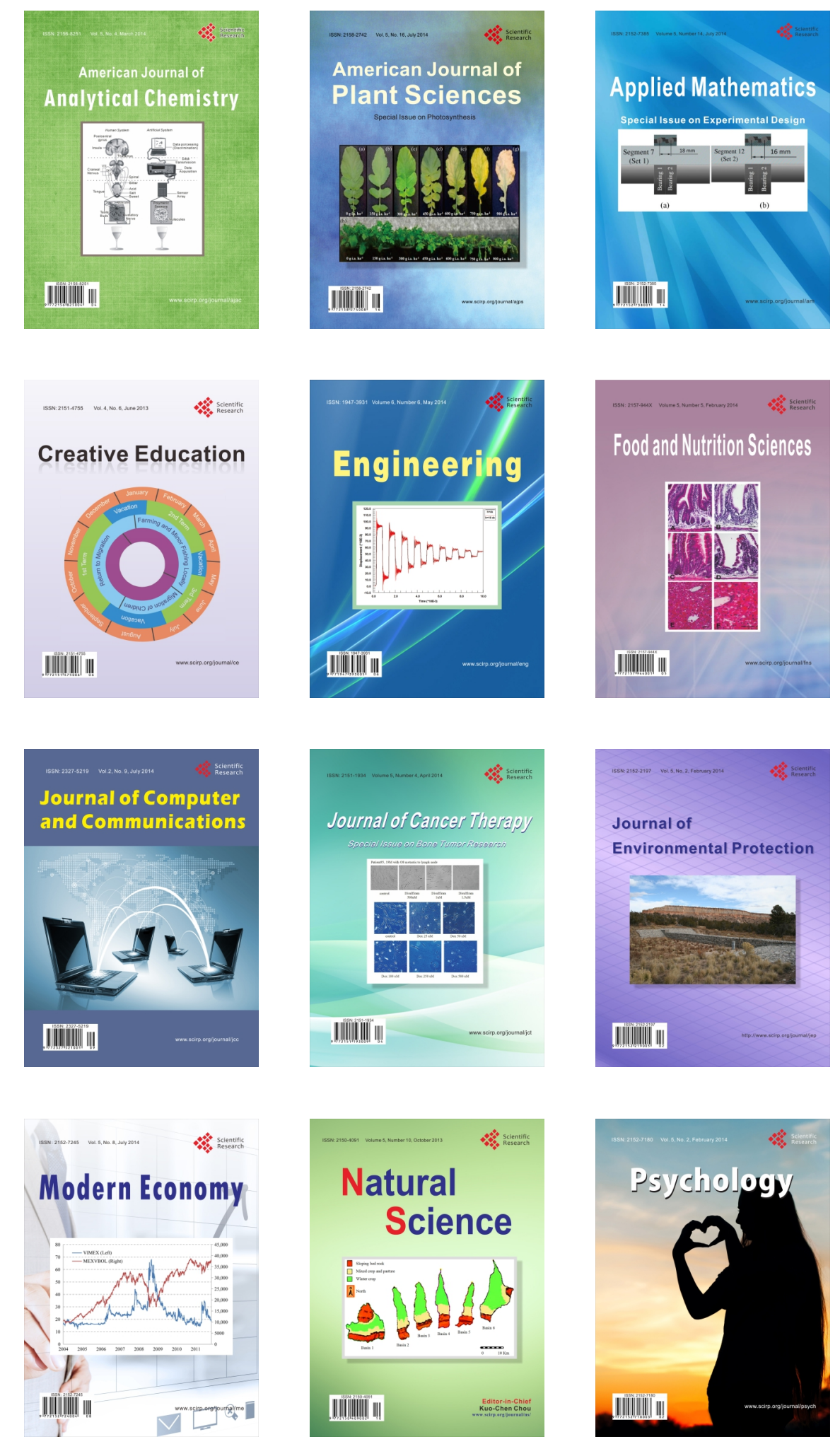